\title{
Fermatean fuzzy TOPSIS-based approach for occupational risk assessment in manufacturing
}

\author{
Muhammet Gul' ${ }^{1} \cdot$ Huai-Wei Lo ${ }^{2} \cdot$ Melih Yucesan $^{3}$
}

Received: 15 March 2021 / Accepted: 28 May 2021 / Published online: 4 July 2021

(c) The Author(s) 2021

\begin{abstract}
The importance of risk assessment in the context of occupational health and safety by manufacturing operators strengthens their hands in solving the problems they may encounter in business processes related to health and safety. One of the most important phases of conducting an exhaustive occupational risk assessment is to analyze potential hazards and associated risks quantitatively. Since manufacturing is one of the industries that require workers to be highly exposed to work, creating a safer environment to reduce occupational injuries is an important task. This study proposes a novel fuzzy risk assessment approach developed by integrating Fermatean fuzzy sets (FFSs) and technique for order preference by similarity to ideal solution (TOPSIS) method for ranking potential hazards in manufacturing. FFSs are a new version of fuzzy set theory that covers the intuitionistic fuzzy sets and Pythagorean fuzzy sets. This version of the fuzzy set is crucial in the decision-making process to handle uncertain information more easily and reflect uncertainty better. A linguistic scale under Fermatean fuzzy documentation has also been developed for experts/decision makers to disclose their judgments easily. Occupational risk analysts can benefit from this approach since FFSs are used for the first time in occupational risk assessment, and the approach is presented in integration with TOPSIS. The proposed approach is applied in the aluminum plate-manufacturing process risk assessment. In the conclusion of the implementation, risks arising in the production are prioritized. In addition, this study made comparisons with other fuzzy methods to demonstrate the proposed approach's difference and practicality. This study's results can support practitioners and risk analysts in formulating the improvement measures to increase the safety of the work environment further.
\end{abstract}

Keywords Fermatean fuzzy set $\cdot$ TOPSIS $\cdot$ Risk assessment $\cdot$ Aluminum plate manufacturing

\section{Introduction}

Manufacturing requires higher physical conditions for workers than in other industries. These workers are exposed to harsh environments for a long time (e.g., high temperature,

Muhammet Gul

muhammetgul@munzur.edu.tr

Huai-Wei Lo

w110168888@gmail.com

Melih Yucesan

melihyucesan@munzur.edu.tr

1 Department of Emergency Aid and Disaster Management, Munzur University, Tunceli, Turkey

2 Department of Industrial Engineering and Management, Chaoyang University of Technology, Taichung, Taiwan

3 Department of Mechanical Engineering, Munzur University, Tunceli, Turkey noise, harmful substances, germs), and often maintain long awkward postures for operations [9, 13, 31]. Although the manufacturing industry has introduced many automated equipment to replace repetitive actions, most of the manufacturing process's operational tasks still require a lot of physical intervention. Therefore, the need for active risk assessment to reduce potential harm cannot be ignored [22].

According to the report of those who had an occupational accident in aluminum production between 2013 and 2019 prepared by the Social Security Institution (SSI) of Turkey, 94.4\% of the people who had an occupational accident were men, and $5.6 \%$ were women. In addition, in $91.47 \%$ of occupational accidents, the person who had an accident started to work on the same day, while $8.53 \%$ became unavailable for two days or more. A total of 9441 occupational accidents have occurred between these years. For this reason, preventing occupational accidents, especially for the aluminum industry, will minimize life and economic losses (URL-1). 
The development of risk assessment can be traced back to 40 years ago. It first conceptualized risk and then established a risk assessment model through quantitative or qualitative analysis approaches, which promoted risk assessment as a separate scientific field [40]. The main task of risk assessment is to use several assessment techniques to diagnose and discover the potential risks of specific activities and formulate improvement actions to suppress the occurrence of risks or delete the causes of risks [4]. In short, in the face of unknown risk events, decision makers hope to accurately grasp the potential risks and formulate appropriate preventive measures to control the damage caused by the risk events [29]. The current risk assessment methods can be divided into three categories: quantitative analysis, semiqualitative-quantitative analysis, and qualitative analysis. Most researchers use semi-qualitative-quantitative analysis to explore occupational hazards in manufacturing because it is difficult to obtain a large amount of complete quantitative data on occupational accidents [34].

It is a feasible practice to assist the assessed event's risk assessment through experts' professional experience and judgment. Many academic studies have pointed out that expert-based risk assessment can obtain more effective and reliable results. Such a research concept forms a typical multicriteria decision-making (MCDM) problem [15, 19, 23-25, 29]. MCDM is one of the soft computing methods that convert qualitative information into quantitative analysis. In addition, it can also process qualitative and quantitative data simultaneously. MCDM does not require a large sample of survey data like the statistical theory. Rezaei et al. [33] pointed out that only needs four to ten experts to obtain reliable information for the MCDM process. Of course, it is necessary to ensure that the interviewed experts are highly relevant and professional. In usual qualitative accurate decision-making issues, it is an unrealistic hypothesis that a decision maker's judgment is so precise in effectively measuring experts' opinions and considering the uncertainty of the evaluation environment. Many studies have applied the fuzzy-based MCDM model to discuss risk assessment issues in manufacturing [15, 19, 21]. For example, applying the fuzzy VIKOR (visekriterijumska optimizacija i kompromisno resenje) in project evaluation for safe route of voice traffic [2], using rough TOPSIS (technique for order preference by similarity to ideal solution) in reliability appraisal of machine tools, [29], employed fuzzy DEMATEL (decision-making trial and evaluation laboratory) in the supply chain's safety assessment [30]. Moreover, some miscellaneous occupational health and safety risk assessment models are released in the recent literature using MCDM methods along with fuzzy sets $(26,27,28)$; [6, 10, 15, 17, 19, 45-47].

Some variant fuzzy theories have gradually been proposed to replace conventional fuzzy theory, such as intuitionistic fuzzy sets (IFs) (3) and Pythagorean fuzzy sets
(PFs) [43], which are used to more accurately reflect the semantics of experts. A novel fuzzy logic, called Fermatean fuzzy sets (FFSs), was proposed by Senapati and Yager [37]. FFSs enhance the ability to measure uncertainty compared to IFs and PFs. The scope of information uncertainty covered by FFs is broader, which is instrumental in avoiding potential information missed in qualitative conversion to quantification. However, existing risk assessment techniques have not incorporated FFs into the MCDM model. This study proposes a new risk assessment model for occupational risk assessment in manufacturing. A new FF-TOPSIS approach in this model considers the uncertainty of the evaluated events and measures the degree of membership and non-membership in the assessment process. During the execution of FF-TOPSIS, the reference points for distance calculation include positive and negative ideal solutions (PIS and NIS), which can obtain more potential information than many other MCDM methods (e.g., simple additive weighting (SAW), weighted aggregated sum product assessment (WASPAS), multi-objective optimization based on ratio analysis (MOORA), and additive ratio assessment (ARAS)). Because FF-TOPSIS can determine the distance between each evaluated item and PIS and NIS. In addition, this approach provides a complete linguistic assessment level and FFSs membership functions.

The FF-TOPSIS approach can be used to obtain the relative closeness index of each hazard and priority them, which can be applied to formulate the appropriate improvement measures of occupational risk for the manufacturing industry. This study collected real-world data from a Turkish aluminum plate-manufacturing company to demonstrate the practicality and effectiveness of the proposed approach. Senapati and Yager [37] prove that FFSs are superior to IFs and PFs, but it has not yet confirmed the difference between grey and conventional (crisp) fuzzy theories. Therefore, this study also compares crisp TOPSIS, grey TOPSIS, and general fuzzy TOPSIS techniques. The results show that the proposed approach improves the above three techniques' limitations, thereby more accurately transforming expert opinions into computable quantitative data. The characteristics of this paper are summarized below.

(i) The proposed risk assessment model brings a new framework for occupational risk assessment in manufacturing.

(ii) This study identifies and discusses 12 sections of the factory and their 85 potential hazards in the aluminum manufacturing in Turkey.

(iii) The FF-TOPSIS approach determines the relative closeness index of each hazard and prioritizes the 85 potential hazards. 
(iv) The results of this study can support practitioners and risk analysts in formulating improvement measures.

(v) The execution of the model comparison illustrates the advantages of the proposed model.

The remainder of this paper is organized as follows. The next section presents a literature review of manufacturing risk assessment and FFSs, and then explains the research gaps. The third section introduces the FF-TOPSIS methodology and the proposed risk assessment model. The fourth section presents a case study to illustrate the practicality and effectiveness of the proposed model. Then, some discussions and execution model comparisons are provided. The last section summarizes the conclusions and provides suggestions for future research.

\section{Literature review}

In this section, a brief overview of previous studies regarding manufacturing risk assessment and FFSs are provided. Then, the research gap and contributions are given in the lights of both reviews.

\section{Review of manufacturing risk assessment}

The issues related to occupational health and safety in the workplace environment have always been problems faced by companies. To improve workplace safety and reduce accident rates, these issues must be considered for the sake of improving companies' operations [16]. According to Berhan [7], there are about 268 million work-related diseases and non-fatal workplace accidents worldwide every year. It is an important task to actively examine and evaluate workers' workplace safety issues, otherwise, work efficiency and the social economy will be affected. Since the manufacturing industry requires workers to be highly involved in production operations, it has become one of the industries with the highest frequency of occupational accidents [13].

The risk assessment process is applied to determine risk improvement priorities by assessing the rating of risks. Existing quantitative, semi-qualitative-quantitative, and qualitative and hybrid risk assessment approaches are used in various manufacturing industries [34]. Take research on occupational safety, for example, Dabbagh and Yousefi [11] proposed a three-stage model for identifying auto-parts manufacturing companies' occupational health and safety. First, they use the failure mode and effect analysis (FMEA) to identify potential risks. The evaluation criteria used include severity, occurrence, detection, cost, and time, and then fuzzy cognitive map (FCM) is used to assign the weights of the criteria. Finally, the first two stages' output data are used as an assessment matrix, and MOORA is used to determine the priority of risks. Li et al. [22] developed an improved physical demand analysis (PDA) for manufacturing. Their proposed risk analysis framework focuses on ergonomic risk assessment, identification, control, and mitigation. Rezaee et al. [32] employed a risk analysis in the chemical industry from the health, safety and environmental perspectives. Their model includes FMEA, fuzzy inference system and fuzzy DEA. Gul et al. [18] performed an improved version of Fine-Kinney method with hexagonal fuzzy sets and MULTIMOORA to assess risks in a cement manufacturing plant. Delice and Can [12] carried out an ergonomic risk assessment for the tube manufacturing industry. In their study, Modified Kemeny Median Indicator Ranks Accordance (KEMIRA-M) and a novel two-dimensional best-worst method (BWM) are integrated for weighting ergonomic risk criteria. Then, the rankings of workers were determined via MOORA.

Focusing on the systems or products, Braglia et al. [8] established a risk failure deployment (RFD) tool to analyze the train access door's installation process. RFD is used to detect the most critical failure modes and provides practical step-by-step guidance for risk analysts to eliminate/mitigate/ control risk root causes. Lo et al. [29] developed a hybrid MCDM risk assessment framework to provide a reliability analysis tool for the machine tool manufacturing. Their study integrates rough set theory, BWM, and TOPSIS to explore and review the potential causes of product failure. Ali et al. [2] performed a risk assessment of China-Pakistan fiber optic project using fuzzy VIKOR method. Their research proposes strategies to increase the fiber optic project's security and reliability between China and Pakistan. The above studies have made many breakthroughs and contributions to the risk assessment of manufacturing.

\section{Review of Fermatean fuzzy sets}

Since this type of fuzzy sets are recently developed [37], there are limited papers in the literature on the theoretical improvement of FFSs or applying this set to a real-world problem. In the first study of FFSs, Senapati and Yager [37] compared FFSs with PFSs and IFs. Mathematical operators and fundamental set of operations for this type of fuzzy sets are defined as well as score and accuracy functions for ranking. In addition, in the first paper, the computation of Euclidean distance is explained. Following the first study, it is applied to MCDM problems [1, 5, 14, 23, 24, 35, 36, 42], 1. Moreover, Sergi and Sari [38] applied FFSs to engineering economics problems. Fuzzy capital budgeting methods, including fuzzy net present worth, fuzzy net future worth and fuzzy net annual worth are extended using FFSs with some illustrative calculations Sergi and Sari [38]. From theoretical aspects, Silambarasan [39] suggested new operators for FFSs. While Liu

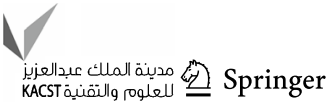


et al. [23] proposed Fermatean fuzzy linguistic set and applied it to the MCDM problems. Liu et al. [24] focus on distance measure for Fermatean fuzzy linguistic term sets based on linguistic scale function.

From this short literature review, it can be easily inferred that applications of this type of fuzzy sets to the MCDM problems are in progress. In this regard, implementing FFSs integrated with MCDM methods to any real-life problems has gained importance. Therefore, in this study, we aim to apply Fermatean fuzzy TOPSIS in the manufacturing risk assessment problem.

\section{Research gap and contributions}

The provided short literature reviews on both manufacturing risk assessment and FFSs reveal that fuzzy set extension and MCDM in the risk assessment domain have several pluses. In this regard, the following contributions are pointed out from this study to the current literature.

(i) FFSs in TOPSIS (with MCDM concept) have been implemented in a real-life occupational risk assessment problem for manufacturing in the literature. Considering the risk assessment's width (from occupational health and safety perspective to financial risk assessment), this study will lead future studies in this field.

(ii) For FF-TOPSIS computations, a new linguistic scale under Fermatean fuzzy documentation has also been developed for experts to disclose their judgments easily. The scope of information uncertainty covered by Fermatean fuzzy is broader than that conventional fuzzy, intuitionistic fuzzy, and Pythagorean fuzzy, which is instrumental in avoiding potential information missed in qualitative conversion to quantification. Scholars may benefit from this scale in future studies. In addition, FF-TOPSIS uses PIS and NIS as the reference points for distance calculation, which can obtain more potential information.

(iii) Practitioners in the industry can adapt the case application presented in this study for their risk assessment processes. From this point, a good practice is demonstrated with detailed steps from expert judgments to risk preventive measure suggestions.

(iv) A comparative analysis is provided to test the solidity of the proposed approach. To do this, crisp TOPSIS, fuzzy TOPSIS, and grey TOPSIS are applied to the problem. Their analysis results are not exactly the same as FF-TOPSIS. Since the FFs measure both the membership and non-membership, but crisp, fuzzy, and grey theories only consider the membership.

\section{Methodology}

In this section, preliminaries of FFS are introduced. Then, procedural steps of FF-TOPSIS are presented with its descriptive formulations.

\section{Preliminaries on Fermatean fuzzy sets (FFSs)}

Definition 1 Let $X$ be universe of discourse. A FFS $\mathcal{F}$ in $X$ is an object having the form

$\mathcal{F}=\left\{\left\langle x, \mu_{F}(x), \vartheta_{F}(x)\right\rangle: x \in X\right\}$,

where $\mu_{F}(x): X \rightarrow[0,1]$ and $\vartheta_{F}(x): X \rightarrow[0,1]$ including the condition.

$0 \leq\left(\mu_{F}(x)\right)^{3}+\left(\vartheta_{F}(x)\right)^{3} \leq 1$.

For all $x \in X$. The $\mu_{F}(x)$ and $\vartheta_{F}(x)$ refer to the degree of membership and non-membership of the element $\mathrm{x}$ in the set $\mathcal{F}$, respectively.

For any FFS $\mathcal{F}$ and $x \in X$,

$\pi_{F}(x)=\sqrt[3]{1-\left(\mu_{F}(x)\right)^{3}+\left(\vartheta_{F}(x)\right)^{3}}$,

can be identified as the degree of indeterminacy of $x$ to $\mathcal{F}$.

Demonstration of a comparison between intuitionistic, Pythagorean, and FFSs is as in Fig. 1. Intuitionistic membership grades (IMGs) are all points beneath the $\mu(x)+\vartheta(x) \leq 1$. Pythagorean membership grades (PMGs) are all point with $\left(\mu_{P}(x)\right)^{2}+\left(\vartheta_{P}(x)\right)^{2} \leq 1$ and the Fermatean membership grades (FMGs) are all point

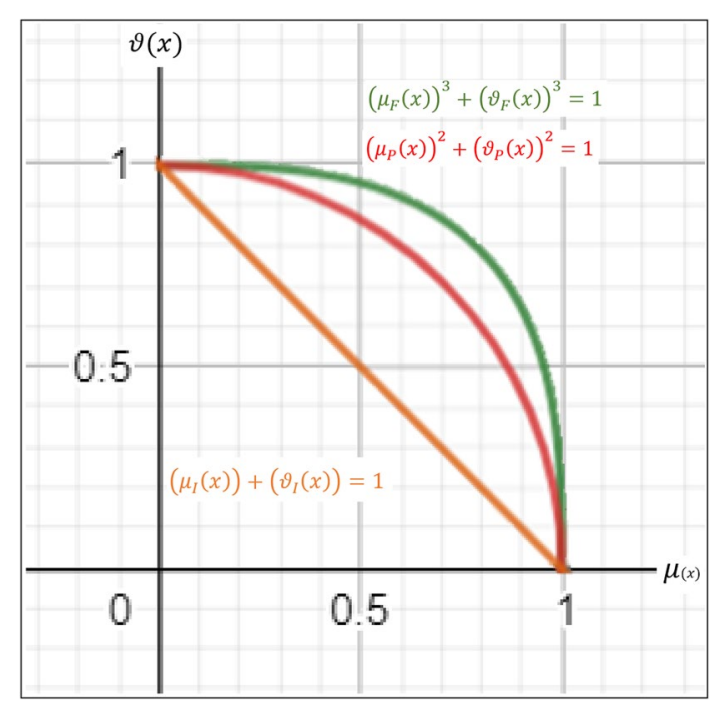

Fig. 1 A comparative demonstration of three membership grades 
$\left(\mu_{F}(x)\right)^{3}+\left(\vartheta_{F}(x)\right)^{3} \leq 1$. FMGs allow higher non-membership grades than both IMGs and PMGs.

For a more straightforward usage, we will use the symbol $\mathcal{F}=\left(\mu_{F}, \vartheta_{F}\right)$ for the FFS $\mathcal{F}=\left\{\left\langle x, \mu_{F}(x), \vartheta_{F}(x)\right\rangle: x \in X\right\}$.

Definition 2 Let $\mathcal{F}=\left(\mu_{F}, \vartheta_{F}\right), \quad \mathcal{F}_{1}=\left(\mu_{F_{1}}, \vartheta_{F_{1}}\right)$ and $\mathcal{F}_{2}=\left(\mu_{F_{2}}, \vartheta_{F_{2}}\right)$ be three FFSs, then some operations are defined as below:

(i) $\mathcal{F}_{1} \cap \mathcal{F}_{2}=\left(\min \left\{\mu_{F_{1}}, \vartheta_{F_{2}}\right\}, \max \left\{\vartheta_{F_{1}}, \vartheta_{F_{2}}\right\}\right)$;

(ii) $\mathcal{F}_{1} \cup \mathcal{F}_{2}=\left(\max \left\{\mu_{F_{1}}, \vartheta_{F_{2}}\right\}, \min \left\{\vartheta_{F_{1}}, \vartheta_{F_{2}}\right\}\right)$;

(iii) $\mathcal{F}^{c}=\left(\vartheta_{F}, \mu_{F}\right)$.

Definition 3 Let $\mathcal{F}=\left(\mu_{F}, \vartheta_{F}\right), \quad \mathcal{F}_{1}=\left(\mu_{F_{1}}, \vartheta_{F_{1}}\right)$ and $\mathcal{F}_{2}=\left(\mu_{F_{2}}, \vartheta_{F_{2}}\right)$ be three FFSs and $\lambda>0$, then some mathematical operations are formulized as below:

(i) $\mathcal{F}_{1} \boxplus \mathcal{F}_{2}=\left(\sqrt[3]{\mu_{F_{1}}{ }^{3}+\mu_{F_{2}}{ }^{3}-\mu_{F_{1}}{ }^{3} \mu_{F_{2}}{ }^{3}}, \vartheta_{F_{1}} \vartheta_{F_{2}}\right)$;

(ii) $\mathcal{F}_{1} \otimes \mathcal{F}_{2}=\left(\mu_{F_{1}} \mu_{F_{2}}, \sqrt[3]{\vartheta_{F_{1}}{ }^{3}+\vartheta_{F_{2}}{ }^{3}-\vartheta_{F_{1}}{ }^{3} \vartheta_{F_{2}}{ }^{3}}\right)$;

(iii) $\lambda \mathcal{F}=\left(\sqrt[3]{1-\left(1-\mu_{F}^{3}\right)^{\lambda}}, \vartheta_{F}^{\lambda}\right)$;

(iv) $\mathcal{F}^{\lambda}=\left(\mu_{F}^{\lambda}, \sqrt[3]{1-\left(1-\vartheta_{F}^{3}\right)^{\lambda}}\right)$.

Another important point in FFSs is the ranking of two Fermatean fuzzy numbers. For this, a score function computation is given as in Definition 4.

Definition 4 Let $\mathcal{F}=\left(\mu_{F}, \vartheta_{F}\right)$ be a FFS, then the score function of $\mathcal{F}$ is as follows: $\operatorname{score}(\mathcal{F})=\mu_{F}{ }^{3}-\vartheta_{F}{ }^{3}$

For any FFS $\mathcal{F}=\left(\mu_{F}, \vartheta_{F}\right)$, the proposed score function $\operatorname{score}(\mathcal{F}) \in[-1,1]$

Definition 5 Let $\mathcal{F}_{1}=\left(\mu_{F_{1}}, \vartheta_{F_{1}}\right)$ and $\mathcal{F}_{2}=\left(\mu_{F_{2}}, \vartheta_{F_{2}}\right)$ be two FFSs, a natural quasi-ordering is as below:

$\mathcal{F}_{1} \geq \mathcal{F}_{2}$ if and only if $\mu_{F_{1}} \geq \mu_{F_{2}}$ and $\vartheta_{F_{1}} \leq \vartheta_{F_{2}}$

In Definitions 6 and 7, the relation between FFSs is defined.

Definition 6 Let $\mathcal{F}_{1}=\left(\mu_{F_{1}}, \vartheta_{F_{1}}\right)$ and $\mathcal{F}_{2}=\left(\mu_{F_{2}}, \vartheta_{F_{2}}\right)$ be two FFSs, score $\left(\mathcal{F}_{1}\right)$ and score $\left(\mathcal{F}_{2}\right)$ be score function of $\mathcal{F}_{1}$ and $\mathcal{F}_{2}$, respectively, then

1. If $\operatorname{score}\left(\mathcal{F}_{1}\right)<\operatorname{score}\left(\mathcal{F}_{2}\right)$, then $\mathcal{F}_{1}<\mathcal{F}_{2}$;

2. If score $\left(\mathcal{F}_{1}\right)>\operatorname{score}\left(\mathcal{F}_{2}\right)$, then $\mathcal{F}_{1}>\mathcal{F}_{2}$;

3. If $\operatorname{score}\left(\mathcal{F}_{1}\right)=\operatorname{score}\left(\mathcal{F}_{2}\right)$, then $\mathcal{F}_{1} \sim \mathcal{F}_{2}$;

Definition 7 Let $\mathcal{F}=\left(\mu_{F}, \vartheta_{F}\right)$, be an FFS, then an accuracy function is computed as below:
$\operatorname{acc}(\mathcal{F})=\mu_{F}{ }^{3}+\vartheta_{F}{ }^{3}$

Clearly $\operatorname{acc}(\mathcal{F}) \in[0,1]$. In fact

$0 \leq \operatorname{acc}(\mathcal{F})=\mu_{F}{ }^{3}+\vartheta_{F}{ }^{3} \leq 1$.

Definition 8 Let $\mathcal{F}_{1}=\left(\mu_{F_{1}}, \vartheta_{F_{1}}\right)$ and $\mathcal{F}_{2}=\left(\mu_{F_{2}}, \vartheta_{F_{2}}\right)$ be two FFSs, score $\left(\mathcal{F}_{i}\right)$ and $\operatorname{acc}\left(\mathcal{F}_{i}\right)(i=1,2)$ are given for $\mathcal{F}_{1}$ and $\mathcal{F}_{2}$, respectively, then

1. If $\operatorname{score}\left(\mathcal{F}_{1}\right)<\operatorname{score}\left(\mathcal{F}_{2}\right)$, then $\mathcal{F}_{1}<\mathcal{F}_{2}$;

2. If $\operatorname{score}\left(\mathcal{F}_{1}\right)>\operatorname{score}\left(\mathcal{F}_{2}\right)$, then $\mathcal{F}_{1}>\mathcal{F}_{2}$;

3. If $\operatorname{score}\left(\mathcal{F}_{1}\right)=\operatorname{score}\left(\mathcal{F}_{2}\right)$, then

(i) If $\operatorname{acc}\left(\mathcal{F}_{1}\right)<\operatorname{acc}\left(\mathcal{F}_{2}\right)$, then $\mathcal{F}_{1}<\mathcal{F}_{2}$;

(ii) If $\operatorname{acc}\left(\mathcal{F}_{1}\right)>\operatorname{acc}\left(\mathcal{F}_{2}\right)$, then $\mathcal{F}_{1}>\mathcal{F}_{2}$;

(iii) If $\operatorname{acc}\left(\mathcal{F}_{1}\right)=\operatorname{acc}\left(\mathcal{F}_{2}\right)$, then $\mathcal{F}_{1}=\mathcal{F}_{2}$;

Definition 9 Let $\mathcal{F}_{1}=\left(\mu_{F_{1}}, \vartheta_{F_{1}}\right)$ and $\mathcal{F}_{2}=\left(\mu_{F_{2}}, \vartheta_{F_{2}}\right)$ be two FFSs. The Euclidean distance between $\mathcal{F}_{1}$ and $\mathcal{F}_{2}$ is

$d\left(\mathcal{F}_{1}, \mathcal{F}_{2}\right)=\sqrt{1 / 2\left[\left(\mu_{F_{1}}{ }^{3}-\mu_{F_{2}}{ }^{3}\right)^{2}+\left(\vartheta_{F_{1}}{ }^{3}-\vartheta_{F_{2}}{ }^{3}\right)^{2}+\left(\pi_{F_{1}}{ }^{3}-\pi_{F_{2}}{ }^{3}\right)^{2}\right]}$.

\section{Fermatean fuzzy technique for order preference by similarity to ideal solution (FF-TOPSIS)}

FF-TOPSIS includes the following five steps in the problem.

Step 1: For an MCDM problem with Fermatean fuzzy numbers (FFNs), we formulate the Fermatean risk assessment matrix $R=\left(C_{j}\left(S_{i}\right)\right)_{m x n}$ with Eq. (1) where $C_{j}\left(S_{i}\right)(j=1,2, \ldots, n i=1,2, \ldots, m)$ refers to the hazard $S_{i} \in X$ regarding the risk parameter $C_{j} \in C$.

$w=\left(w_{1}, w_{2}, \ldots, w_{n}\right)^{T}$ demonstrates the risk parameters weights with $0 \leq w_{j} \leq 1, j=1,2, \ldots, n$ and $\sum_{j=1}^{n} w_{j}=1$. We show the performance value of the hazard $S_{i}$ with respect to the risk parameter $C_{j}$ by $C_{j}\left(S_{i}\right)=\left(\mathcal{U}_{i j}, v_{i j}\right)$.

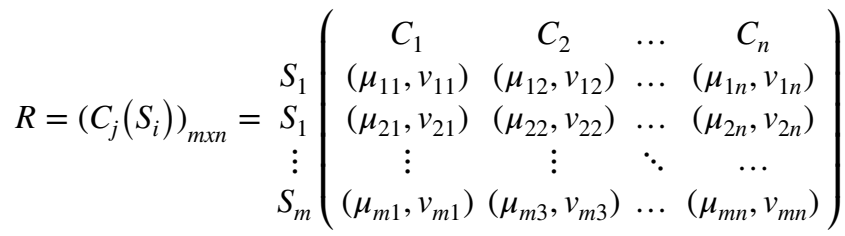

Step 2: By Eqs. (2) and (3), the Fermatean fuzzy positive ideal solution (FFPIS) $S^{+}=\left\{C_{1}\left(S^{+}\right), C_{2}\left(S^{+}\right), \ldots, C_{n}\left(S^{+}\right)\right\}$and the 
Fermatean fuzzy negative ideal solution (FFNIS) $S^{-}=\left\{C_{1}\left(S^{-}\right), C_{2}\left(S^{-}\right), \ldots, C_{n}\left(S^{-}\right)\right\}$are determined.

$S^{+}=\left\{\begin{array}{l}\max _{i}\left\langle\operatorname{score}\left(C_{j}\left(S_{i}\right)\right)\right\rangle \mid \quad j=1,2, \ldots, n \\ \text { if } c_{j} \text { is benefit criterion } \\ \min _{i}\left\langle\operatorname{score}\left(C_{j}\left(S_{i}\right)\right)\right\rangle \mid j=1,2, \ldots, n \\ \text { if } c_{j} \text { is a cost criterion }\end{array}\right.$

$S^{+}=\left\{\left(\mu_{1}^{+}, v_{1}^{+}\right),\left(\mu_{2}^{+}, v_{2}^{+}\right), \ldots,\left(\mu_{n}^{+}, v_{n}^{+}\right)\right\}$.

$S^{-}=\left\{\begin{array}{l}\min _{i}\left\langle\operatorname{score}\left(C_{j}\left(S_{i}\right)\right)\right\rangle \mid \quad j=1,2, \ldots, n \\ \text { if } c_{j} \text { is benefit criterion } \\ \max _{i}\left\langle\operatorname{score}\left(C_{j}\left(S_{i}\right)\right)\right\rangle \mid j=1,2, \ldots, n \\ \text { if } c_{j} \text { is a cost criterion }\end{array}\right.$

$S^{-}=\left\{\left(\mu_{1}^{-}, v_{1}^{-}\right),\left(\mu_{2}^{-}, v_{2}^{-}\right), \ldots,\left(\mu_{n}^{-}, v_{n}^{-}\right)\right\}$.

Step 3: Distances from FFPIS and FFNIS are computed using Eqs. (4) and (5), respectively:

\section{Proposed risk assessment model}

The procedural steps of the proposed risk assessment model are given in Fig. 2. There are two main phases as follows: (1) pre-assessment phase, which includes determination of potential hazards and deciding on both weights for risk parameters and experts, and (2) application of risk assessment by FF-TOPSIS.

The pre-assessment phase contains determination of the following arguments: (1) the definition of the problems (aluminum plate-manufacturing process risk assessment), (2) risk parameters (probability and severity), (3) hazard list (a total of 85 hazards in 12 different sections of the plant), (4) OHS expert, and (5) linguistic terms with their corresponding Fermatean fuzzy numbers. The application phase demonstrates the implementation of FF-TOPSIS to determine the ranking of hazards and associated risks. The experts define the risk assessment problem considering these dimensions. A unit-based hazard list is created. There are 12 sections as casting section, casting lines, carpentry workshop, finished

$$
\begin{aligned}
D\left(S_{i}, S^{+}\right) & =\sum_{j=1}^{n} w_{j} d\left(C_{j}\left(S_{i}\right), C_{j}\left(S^{+}\right)\right) \\
D\left(S_{i}, S^{+}\right) & =\sum_{j=1}^{n} w_{j} \sqrt{\frac{1}{2}\left[\left(\mu_{i j}{ }^{3}-\left(\mu_{j}^{+}\right)^{3}\right)^{2}+\left(\vartheta_{i j}{ }^{3}-\left(\vartheta_{j}^{+}\right)^{3}\right)^{2}+\left(\pi_{i j}{ }^{3}-\left(\pi_{j}^{+}\right)^{3}\right)\right]} \\
i & =1,2, \ldots, m .
\end{aligned}
$$$$
D\left(S_{i}, S^{-}\right)=\sum_{j=1}^{n} w_{j} d\left(C_{j}\left(S_{i}\right), C_{j}\left(S^{-}\right)\right)
$$$$
D\left(S_{i}, S^{-}\right)=\sum_{j=1}^{n} w_{j} \sqrt{\frac{1}{2}\left[\left(\mu_{i j}{ }^{3}-\left(\mu_{j}^{-}\right)^{3}\right)^{2}-\left(\vartheta_{i j}{ }^{3}-\left(\vartheta_{j}^{-}\right)^{3}\right)^{2}-\left(\pi_{i j}{ }^{3}-\left(\pi_{j}^{-}\right)^{3}\right)\right]} .
$$

Step 4: By Eq. (6), revised closeness $\xi\left(S_{i}\right)$ of each hazard $\left.S_{i} i=1,2, \ldots, m\right)$ is computed:

$\xi\left(S_{i}\right)=\frac{D\left(S_{i}, S^{-}\right)}{D_{\max }\left(S_{i}, S^{-}\right)}-\frac{D\left(S_{i}, S^{+}\right)}{D_{\min }\left(S_{i}, S^{+}\right)}$.

Step 5: The revised closeness $\xi\left(S_{i}\right)$ in Step 4 is used to decide the order of hazards and to identify suitable hazards. $\xi\left(S_{i}\right)$ values are listed in descending order. The risk parameter with the highest $\xi\left(S_{i}\right)$ value is determined, and ranking is made:

$S^{*}=\left\{S_{i}:\left(i: \xi\left(S_{i}\right)=\max _{1 \leq l \leq m} \xi\left(x_{l}\right)\right\}\right.$. goods stock section, production section, packing section, slicing section, sizing section, washing and stretching section, cold rolling section, technical maintenance section, and factory site. Which risk parameters will be used in risk assessment and what their weight will be are determined according to the expert opinions and the literature. Two parameters named probability and severity are considered for the approach by assigning a weight of $60 \%$ and $40 \%$ for each one, respectively. Another crucial dimension in the pre-assessment phase is the OHS expert profile and their weight coefficient determination. The weight coefficient assignment procedure followed in the proposed approach is adapted from the literature. It is based on some characteristics such as their job title, educational sage, age, and experience (related to OHS and aluminum production). As the last dimension of the pre-assessment, the approach 


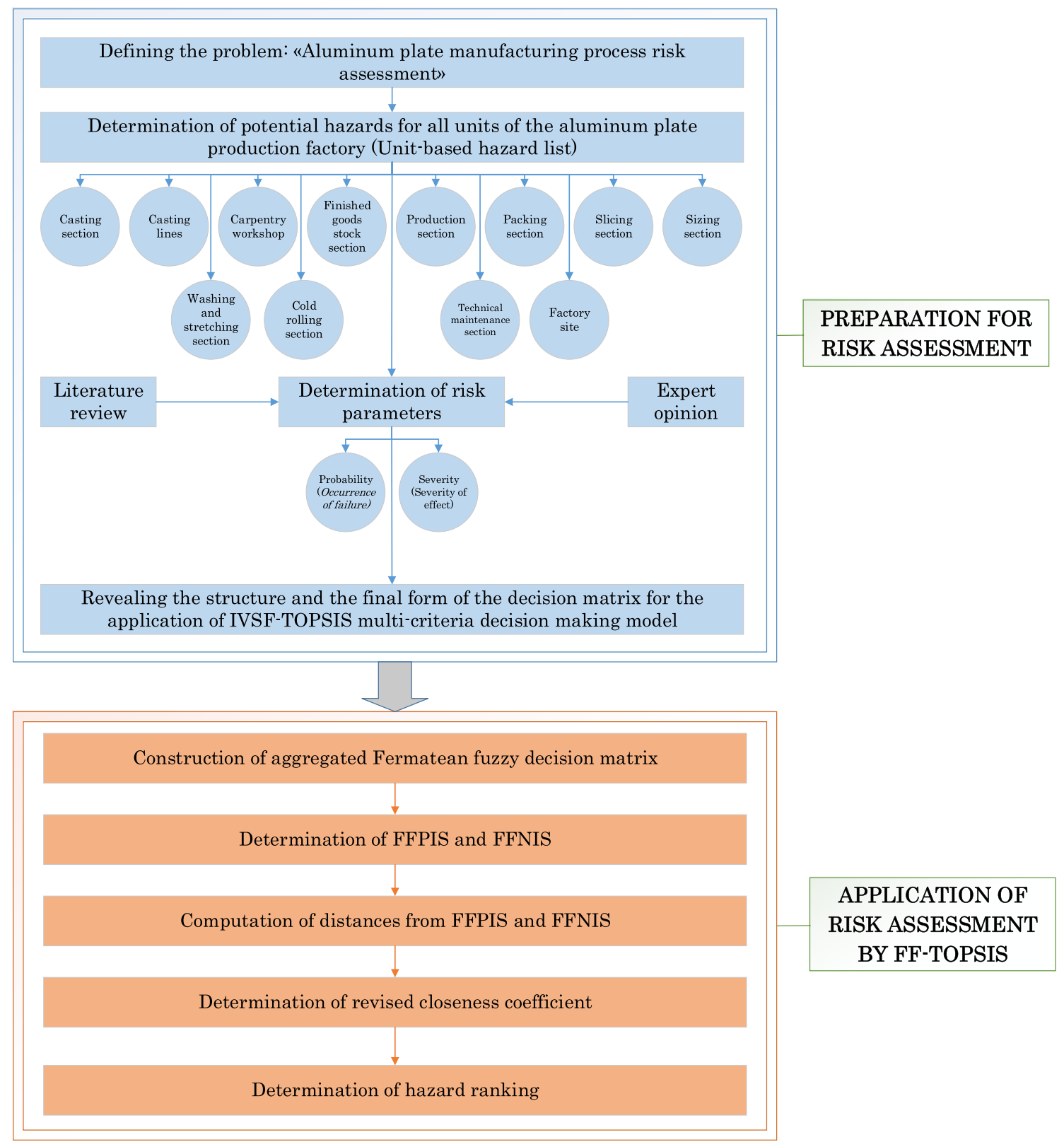

Fig. 2 Procedural steps in the proposed risk assessment model

uses a scale with linguistic terms and their corresponding Fermatean fuzzy numbers. The scale is developed by the authors considering general natural quasi-ordering rules of Fermatean fuzzy sets.

The application phase of risk assessment via FF-TOPSIS also has five sub-steps. Initially, Fermatean fuzzy decision matrix for each expert is aggregated. Second, FFPIS and FFNIS values are computed. In the third sub-step, distance is calculated from both FFPIS and FFNIS. In the fourth and final sub-steps, respectively, revised closeness coefficient (special for the FF-TOPSIS) is obtained for each hazard and ranking is ordered.

\section{Case study}

This case study section is divided into four subsections. First, the studied aluminum plate-manufacturing process is introduced. Then, in the second subsection, the hazard and risk identification is addressed. In the third subsection, the implementation of the approach in a manufacturing process is handled. Finally, a comparative study between the results of this study and some benchmarking studies is performed. 


\section{Studied aluminum plate-manufacturing process}

A case study in an aluminum plate-manufacturing plant is performed to demonstrate the proposed risk assessment model. The observed plant provides high-quality products for domestic and foreign sectors such as automotive, durable goods, electronics, construction, packaging, and energy. The production facility has a high annual production capacity for plain coil and strip, embossed coil and strip, and plain or embossed coil aluminum production. The plant's production lines offer a wide portfolio of products from thickness to widths with various packaging forms that correspond to their specific needs and requirements.

\section{Hazard and risk identification}

The proposed risk assessment model aims to effectively minimize the consequences of hazards and suggest preventive measures in mitigating risks. In this case study, the proposed model's 85 hazards and related risks in 12 different sections of the observed plant are evaluated under 2 risk parameters. The risk parameters are described as follows: "Probability" is defined regarding the occurrence of the risk occurring as a result of the hazard. "Severity" is defined as the most probable results of a potential accident, including injuries and property damages. Detailed information regarding the identification of each hazard is given in Table 1. They are encoded with different IDs so that it is related to the section where it emerged. They are assessed under 12 different sections inside the plant. These sections are presented in Fig. 2.

Five experts with almost the same expertise levels in the aluminum plate-manufacturing industry performed the evaluations. A description of the experts' profiles can be found in Table 2.

In particular, these experts were selected considering their job title, educational sage, age, and experience (related to OHS and aluminum production). In this study's risk assessment phase, it is required to use the importance weights of experts. Therefore, the priority weights of experts are calculated using a procedure from the literature. Considering these rules of Kabir et al. [20] and Yazdi [44], a fixed weight coefficient of 0.2 is assigned for each one as in Table 3 .

The linguistic terms and corresponding Fermatean fuzzy numbers used in the ranking of hazards are given in Table 4 .

\section{Implementation of the approach to the manufacturing process}

In the implementation of the approach, FF-TOPSIS procedural steps given in "Fermatean fuzzy technique for order preference by similarity to ideal solution (FF-TOPSIS)" are followed. Using the linguistic terms given in Table 2 by five experts, first, we obtain the aggregated Fermatean risk assessment matrix. We separately applied FF-TOPSIS for the hazards that emerged at each unit. Therefore, the obtained results are demonstrated according to the unit-based structure. As an example of obtaining the initial aggregated Fermatean risk assessment matrix for "Casting section" hazards, the computations are made in Fig. 3. Fermatean fuzzy weighted average operator, as indicated by Senapati and Yager [35], is applied to obtain an aggregated values of experts in a single decision matrix. After this step, using Eqs. $(2,3)$, FFPIS, and FFNIS values are calculated. To do this, score functions of each hazard (TO1, TO2, TO3, TO4, TO5 and TO6) are computed as in Definition 4 in "Preliminaries on Fermatean fuzzy sets (FFSs)". The score function values of each hazard with respect to the probability parameter are as follows:

score $(\mathrm{TO} 1)=(0.512)^{3}-(0.920)^{3}=-0.644$,

score $(\mathrm{TO} 2)=(0.586)^{3}-(0.836)^{3}=-0.383$,

score $(\mathrm{TO} 3)=(0.828)^{3}-(0.634)^{3}=0.313$,

score $(\mathrm{TO} 4)=(0.514)^{3}-(0.914)^{3}=-0.628$,

$\operatorname{score}($ TO5 $)=(0.890)^{3}-(0.470)^{3}=0.601$,

score $($ TO6 $)=(0.710)^{3}-(0.774)^{3}=-0.106$.

Similarly, the score function values of each hazard with respect to severity parameter are calculated as follows (Fig. 3):

$\operatorname{score}(\mathrm{TO} 1)=(0.732)^{3}-(0.722)^{3}=0.016$,

score $(\mathrm{TO} 2)=(0.690)^{3}-(0.820)^{3}=-0.223$,

$\operatorname{score}(\mathrm{TO} 3)=(0.756)^{3}-(0.712)^{3}=0.071$,

$\operatorname{score}(\mathrm{TO} 4)=(0.752)^{3}-(0.656)^{3}=0.143$,

score $($ TO5 $)=(0.828)^{3}-(0.634)^{3}=0.313$,

score $($ TO6 $)=(0.920)^{3}-(0.510)^{3}=0.646$.

From the score functions, using Eqs. (2-3), $S^{+}$and $S^{-}$ values are obtained as follows:

$S^{+}=\{(0.890,0.470),(0.920,0.510)\}$,

$S^{-}=\{(0.512,0.920),(0.690,0.820)\}$.

Then, using Eqs. (4-6), distances from FFPIS and FFNIS and final revised closeness values are obtained as 
Table 1 Hazard list

\begin{tabular}{|c|c|c|}
\hline Section & ID & Description of the hazard \\
\hline \multirow[t]{6}{*}{ Casting section } & TO1 & Lung diseases caused by inhalation of slag dust \\
\hline & $\mathrm{TO} 2$ & Risk of explosion from armatures \\
\hline & TO3 & Fire caused by overheating inside the cabinet \\
\hline & TO4 & Loss of limb due to hand contact with rotating parts \\
\hline & TO5 & Spread of slag dust \\
\hline & TO6 & Opening the cabinet door inwards \\
\hline \multirow[t]{6}{*}{ Casting lines } & DH1 & Molten aluminum splashes \\
\hline & $\mathrm{DH} 2$ & Falling or tipping of stored materials \\
\hline & DH3 & Intervention due to liquid aluminum overflowing from runner or heat box \\
\hline & DH4 & Fire due to molten aluminum overflowing from the mold \\
\hline & DH5 & Sensitivity or burns on the skin caused by exposure to excessive heat in front of the oven \\
\hline & DH6 & Accidents due to slowing of reflexes, sleepiness, and feeling of extreme tiredness \\
\hline \multirow[t]{9}{*}{ Carpentry workshop } & M1 & Fire in the department \\
\hline & M2 & Injury while using cutting equipment \\
\hline & M3 & Hearing loss due to exposure to loud \\
\hline & M4 & Respiratory diseases caused by exposure to wood dust during material cutting \\
\hline & M5 & Eye injury due to burr splashes during material cutting \\
\hline & M6 & Injury due to improper use of the nailing machine \\
\hline & M7 & Injury from contact with hot surfaces \\
\hline & M8 & Electric shock \\
\hline & M9 & Injury due to falling transport pallets \\
\hline \multirow[t]{3}{*}{ Finished goods stock section } & MSH1 & Fire caused by smoking \\
\hline & MSH2 & Forklift accident involving pedestrians \\
\hline & MSH3 & Falling of stored materials \\
\hline \multirow[t]{7}{*}{ Production section } & PU1 & Injury from contact with rotating parts \\
\hline & PU2 & Injury due to improper use of the press \\
\hline & PU3 & $\begin{array}{l}\text { Hand-finger rupture as a result of contact with the operation area (there is a protective cover in front of } \\
\text { the guillotine shears) }\end{array}$ \\
\hline & PU4 & Hand-finger rupture as a result of contact with the operation area (guillotine scissors wear protector) \\
\hline & PU5 & $\begin{array}{l}\text { Hand-finger rupture due to contact with the operation area (protective covers of the drive system are } \\
\text { installed) }\end{array}$ \\
\hline & PU6 & Injury in using the roller straightener \\
\hline & PU7 & Cutting the material passing through the straightener with improper equipment \\
\hline \multirow[t]{9}{*}{ Packing section } & $\mathrm{P} 1$ & Tipping and bursting of tubes \\
\hline & $\mathrm{P} 2$ & Leaking tubes \\
\hline & $\mathrm{P} 3$ & Contact high-temperature nylon material \\
\hline & $\mathrm{P} 4$ & Gas leak in tool or LPG cylinder \\
\hline & P5 & Injury due to forklift crash \\
\hline & P6 & Back and spine disorders caused by carrying packages \\
\hline & $\mathrm{P} 7$ & Injury with the blade used for cutting \\
\hline & P8 & Injury due to material falling from the crane \\
\hline & P9 & Injury due to tipping of the strips during packaging \\
\hline \multirow[t]{4}{*}{ Slicing section } & D1 & Jamming in moving rollers \\
\hline & D2 & Loss of limb due to improper use of guillotine shears \\
\hline & D3 & Injury as a result of the iron apparatus slipping out of the hand \\
\hline & D4 & Hearing loss as a result of high decibel sound during the cutting process \\
\hline \multirow[t]{4}{*}{ Sizing section } & BK1 & Falling or injury due to scrap items not being lifted \\
\hline & BK2 & Lumbar spine disorders that occur during the stringing process \\
\hline & BK3 & Injury to the operation area \\
\hline & BK4 & Hearing loss due to excessive noise during the cutting process \\
\hline
\end{tabular}


Table 1 (continued)

\begin{tabular}{|c|c|c|}
\hline Section & ID & Description of the hazard \\
\hline \multirow[t]{6}{*}{ Washing and stretching section } & YG1 & Uncontrolled movement and rolling of the coils \\
\hline & YG2 & Crushing, jamming as a result of tipping of steel arms \\
\hline & YG3 & Irritation of cleaning solutions as a result of contact with skin and eyes \\
\hline & YG4 & Limb jamming between roller and plate \\
\hline & YG5 & Injury to the operation area \\
\hline & YG6 & Loudly work of motor gearboxes \\
\hline \multirow[t]{10}{*}{ Cold rolling section } & SH1 & Inhalation of toxic rolling oil steam \\
\hline & $\mathrm{SH} 2$ & The rolling oil accumulating on the roll creates slippery ground \\
\hline & SH3 & Falling into gaps as a result of loss of balance, injury \\
\hline & SH4 & Cutting, injury caused by sharp edge during transportation \\
\hline & SH5 & Drowning as a result of the fire detection system tubes discharging $\mathrm{CO}_{2}$ into the environment \\
\hline & SH6 & Injury due to tape rupture during tightening \\
\hline & SH7 & Staying between the steel arms, being crushed \\
\hline & SH8 & Falling into gaps, injury due to lack of protective plates \\
\hline & SH9 & Injury due to contact with hot coils \\
\hline & SH10 & Working in the coil trolley maneuvering area \\
\hline \multirow[t]{14}{*}{ Technical maintenance section } & TB1 & Loss of limb due to hand contact with rotating parts \\
\hline & TB2 & Injury due to burr splashes from the turned material \\
\hline & TB3 & Hand and arm grabbing while cleaning the burrs accumulated in the lathe \\
\hline & TB4 & Falling into the gaps opened during filter pit cleaning \\
\hline & TB5 & Injury from contact with rotating parts \\
\hline & TB6 & Slippery floors caused by oily material spillage during roller changes \\
\hline & TB7 & Using unsuitable equipment while moving the roller with a crane \\
\hline & TB8 & Operator's exposure to welding gas \\
\hline & TB9 & Operator exposure to welding rays \\
\hline & TB10 & Tube burst \\
\hline & TB11 & Limb compression in the spaces in the operation area \\
\hline & TB12 & Burr splashes on the eye in machining operations \\
\hline & TB13 & Falling from high \\
\hline & TB14 & Severe injury, death from electric shock \\
\hline \multirow[t]{7}{*}{ Factory site } & GFS1 & Forklift accident involving pedestrians \\
\hline & GFS2 & Material overturning from forklift \\
\hline & GFS3 & The overturn of the materials carried by the forklift as a result of the failure of the lifting equipment \\
\hline & GFS4 & Forklift dropping the material it carries \\
\hline & GFS5 & Tipping, bursting of tubes \\
\hline & GFS6 & Injury to the operation area \\
\hline & GFS7 & Fall, injury \\
\hline
\end{tabular}

Table 2 Description of experts participating in the decisionmaking team

\begin{tabular}{llllc}
\hline$\#$ & Title & Educational stage & Age & $\begin{array}{l}\text { Experi- } \\
\text { ence } \\
\text { (years) }\end{array}$ \\
\hline Expert-1 & Occupational safety expert & Master of Science & 40 & $\sim 12$ \\
Expert-2 & Occupational safety expert & Master of Science & 47 & $\sim 10$ \\
Expert-3 & Occupational safety expert & $\mathrm{PhD}$ & 39 & $\sim 15$ \\
Expert-4 & Academician in process safety & $\mathrm{PhD}$ & 35 & $\sim 10$ \\
Expert-5 & Academician in process safety & $\mathrm{PhD}$ & 34 & $\sim 10$ \\
\hline
\end{tabular}


Table 3 The weight determination of experts

\begin{tabular}{lllllll}
\hline Score & Title & Education & Age & Experience & Total & Weight \\
\hline Expert-1 & 3 & 4 & 3 & 3 & 13 & $13 / 65=0.20$ \\
Expert-2 & 3 & 4 & 3 & 3 & 13 & $13 / 65=0.20$ \\
Expert-3 & 3 & 5 & 2 & 3 & 13 & $13 / 65=0.20$ \\
Expert-4 & 3 & 5 & 2 & 3 & 13 & $13 / 65=0.20$ \\
Expert-5 & 3 & 5 & 2 & 3 & 13 & $13 / 65=0.20$ \\
& & & & Total & 65 & \\
\hline
\end{tabular}

Table 4 Fermatean fuzzy scale for hazard ranking

\begin{tabular}{|c|c|c|c|}
\hline \multicolumn{2}{|c|}{ Linguistic term for risk parameter } & \multicolumn{2}{|c|}{$\begin{array}{l}\text { Corresponding Fermatean fuzzy } \\
\text { number }\end{array}$} \\
\hline Probability $(\mathrm{P})$ & Severity (S) & Membership $(\mu)$ & $\begin{array}{l}\text { Non-mem- } \\
\text { bership (v) }\end{array}$ \\
\hline Nearly impossible (NI) & None $(\mathrm{N})$ & 0.06 & 0.99 \\
\hline Low (L) & Minor (Mi) & 0.11 & 0.99 \\
\hline Relatively low (RL) & Very low (VL) & 0.27 & 0.98 \\
\hline Moderate (M) & Low (L) & 0.44 & 0.95 \\
\hline Moderately high (MH) & Moderate (M) & 0.56 & 0.90 \\
\hline High $(\mathrm{H})$ & High $(\mathrm{H})$ & 0.69 & 0.82 \\
\hline Repeated failures (RF) & Very high $(\mathrm{VH})$ & 0.81 & 0.67 \\
\hline Very high $(\mathrm{VH})$ & Hazardous with warning (HW) & 0.92 & 0.51 \\
\hline Extremely high $(\mathrm{EH})$ & Hazardous without warning (HWW) & 1.00 & 0.00 \\
\hline
\end{tabular}

in Table 5. According to the results, hazard "TO5: Spread of slag dust" has the most crucial one among six emerged hazards related to the casting section operations. It has a closeness value of zero. It is followed by the hazard of "TO3: Fire caused by overheating inside the cabinet" with a final revised closeness index value of -2.269 . The third place in the ranking is "TO6: Opening the cabinet door inwards" with a closeness value of -2.392 . The remaining ranking order is TO2 $(-6.621)$, TO4 $(-6.747)$, and TO1 $(-7.195)$. The current measure for the TO5 is the usage of a dust mask suitable for the job. However, some additional comments are required: portable dust suction system should be made suitable for dust-making machines working in this area. Regarding corrective measures of TO3, sprinkler, and alarm system should be installed inside the room against possible fire risk. On the other side, a door should be made to allow room to open to the outside for the TO6.

Following the same procedure as summarized above in assessing the hazards and associated risks in the casting section of the observed aluminum plate-manufacturing plant, all hazards in the plant's remaining sections are assessed. Figures 4 and 5 show the final FF-TOPSIS revised closeness coefficient values of each hazard and ranking of them, respectively.

After carrying out the risk assessment, some preventive measures are suggested for the most serious three hazards and their associated risks as determined by the proposed approach. They are provided as in the following:

Control measures for the "Casting line" hazards (DH3, DH6, DH5): Current measure for the DH3 is the usage of personal protective equipment (PPE) in accordance with the intervention of the employees. However, an additional measure is mandatory as follows: systems that prevent liquid aluminum from spilling can be developed. On the other side, a ventilation system suitable for the working environment should be established for the DH6. For "DH5", which is the third most critical hazard, the followings are suggested: (1) mechanical systems should be used to extract slag from furnaces. (2) The suction system of the slag chamber should be strengthened.

Control measures for the "Carpentry workshop" hazards (M6, M8, M5): current safety measure for M6 is that nailers have floor detecting safety gear. Protective shoes and gloves should be worn as additional precautions. The current safety measure for M8 is an extra insulation in the area where the machines are plugged in. In addition, the leakage current relay should be added to the installation. To reduce the effects of M5, personal protective glasses are used during the operation. In addition, cutting saw should be used to reduce the burr that will occur in cutting machines.

Control measures for the "Finished goods stock section" hazard (MSH2, MSH3, MSH1): forklift routes have been determined, and warning signs have been placed. This is the

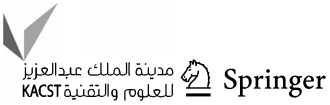




\begin{tabular}{|c|c|c|c|c|c|c|c|c|c|c|c|c|}
\hline \multirow[b]{2}{*}{ Exp1 } & \multicolumn{3}{|c|}{ Prob. } & \multicolumn{3}{|c|}{ Sev. } & & & & & & \\
\hline & $\mu$ & v & $\pi$ & $\mu$ & v & $\pi$ & & & & & & \\
\hline T01 & 0.440 & 0.950 & 0.386 & 0.920 & 0.51 & 0.446 & & & & & & \\
\hline TO2 & 0.440 & 0.950 & 0.386 & 0.690 & 0.82 & 0.493 & & & & & & \\
\hline TO3 & 0.690 & 0.820 & 0.493 & 0.690 & 0.82 & 0.493 & & & & & & \\
\hline TO4 & 0.440 & 0.950 & 0.386 & 0.690 & 0.82 & 0.493 & & & & & & \\
\hline TO5 & 0.920 & 0.510 & 0.446 & 0.920 & 0.51 & 0.446 & & & & & & \\
\hline \multirow[t]{2}{*}{ TO6 } & 0.690 & 0.820 & 0.493 & 0.920 & 0.51 & 0.446 & & & & & & \\
\hline & & Prob. & & & Sev. & & & & & & & \\
\hline Exp2 & $\mu$ & v & $\pi$ & $\mu$ & v & $\pi$ & \multicolumn{2}{|c|}{ Weight of expert } & & & & \\
\hline T01 & 0.440 & 0.950 & 0.386 & 0.440 & 0.950 & 0.386 & Exp1 & 0.2 & & & & \\
\hline TO2 & 0.440 & 0.950 & 0.386 & 0.690 & 0.820 & 0.493 & Exp2 & 0.2 & & & & \\
\hline TO3 & 0.920 & 0.510 & 0.446 & 0.920 & 0.510 & 0.446 & Exp3 & 0.2 & & & & \\
\hline TO4 & 0.690 & 0.820 & 0.493 & 1.000 & 0.000 & 0 & Exp4 & 0.2 & & & & \\
\hline TO5 & 0.920 & 0.510 & 0.446 & 0.690 & 0.820 & 0.493 & Exp5 & 0.2 & & & & \\
\hline \multirow[t]{2}{*}{ T06 } & 0.690 & 0.820 & 0.493 & 0.920 & 0.510 & 0.446 & & & & & & \\
\hline & \multicolumn{3}{|c|}{ Prob. } & \multicolumn{3}{|c|}{ Sev. } & \multicolumn{4}{|c|}{ Prob. } & \multicolumn{2}{|l|}{ Sev. } \\
\hline Exp3 & $\mu$ & v & $\pi$ & $\mu$ & v & $\pi$ & Aggr. & v & $\pi$ & $\mu$ & v & $\pi$ \\
\hline TO1 & 0.560 & 0.900 & 0.457 & 0.690 & 0.820 & 0.493 & T01 0.512 & 0.920 & 0.428 & 0.732 & 0.722 & 0.453 \\
\hline TO2 & 0.920 & 0.510 & 0.446 & 0.690 & 0.820 & 0.493 & TO2 0.586 & 0.836 & 0.419 & 0.690 & 0.820 & 0.493 \\
\hline TO3 & 0.690 & 0.820 & 0.493 & 0.920 & 0.510 & 0.446 & TO3 $\quad 0.828$ & 0.634 & 0.465 & 0.756 & 0.712 & 0.467 \\
\hline TO4 & 0.440 & 0.950 & 0.386 & 0.690 & 0.820 & 0.493 & TO4 0.514 & 0.914 & 0.422 & 0.752 & 0.656 & 0.395 \\
\hline TO5 & 1.000 & 0.000 & 0.000 & 0.690 & 0.820 & 0.493 & TO5 $\quad 0.890$ & 0.470 & 0.366 & 0.828 & 0.634 & 0.465 \\
\hline \multirow[t]{2}{*}{ TO6 } & 0.560 & 0.900 & 0.457 & 0.920 & 0.510 & 0.446 & TO6 0.710 & 0.774 & 0.477 & 0.920 & 0.510 & 0.446 \\
\hline & \multicolumn{3}{|c|}{ Prob. } & \multicolumn{3}{|c|}{ Sev. } & & & & & & \\
\hline Exp4 & $\mu$ & v & $\pi$ & $\mu$ & v & $\pi$ & \multicolumn{6}{|c|}{$(0.440 * 0.2)+\left(0.440^{*} 0.2\right)+(0.560 * 0.2)+(0.560 * 0.2)+(0.560 * 0.2)=0.512$} \\
\hline T01 & 0.560 & 0.900 & 0.457 & 0.690 & 0.820 & 0.493 & & & & & & \\
\hline TO2 & 0.690 & 0.820 & 0.493 & 0.690 & 0.820 & 0.493 & & & & & & \\
\hline TO3 & 0.920 & 0.510 & 0.446 & 0.690 & 0.820 & 0.493 & & & & & & \\
\hline TO4 & 0.560 & 0.900 & 0.457 & 0.690 & 0.820 & 0.493 & & & & & & \\
\hline TO5 & 0.920 & 0.510 & 0.446 & 0.920 & 0.510 & 0.446 & & & & & & \\
\hline \multirow[t]{2}{*}{ TO6 } & 0.690 & 0.820 & 0.493 & 0.920 & 0.510 & 0.446 & & & & & & \\
\hline & \multicolumn{3}{|c|}{ Prob. } & \multicolumn{3}{|c|}{ Sev. } & & & & & & \\
\hline Exp5 & $\mu$ & v & $\pi$ & $\mu$ & v & $\pi$ & & & & & & \\
\hline TO1 & 0.560 & 0.900 & 0.457 & 0.920 & 0.510 & 0.446 & & & & & & \\
\hline TO2 & 0.440 & 0.950 & 0.386 & 0.690 & 0.820 & 0.493 & & & & & & \\
\hline TO3 & 0.920 & 0.510 & 0.446 & 0.560 & 0.900 & 0.457 & & & & & & \\
\hline TO4 & 0.440 & 0.950 & 0.386 & 0.690 & 0.820 & 0.493 & & & & & & \\
\hline TO5 & 0.690 & 0.820 & 0.493 & 0.920 & 0.510 & 0.446 & & & & & & \\
\hline T06 & 0.920 & 0.510 & 0.446 & 0.920 & 0.510 & 0.446 & & & & & & \\
\hline
\end{tabular}

Fig. 3 Demonstration of computation procedure for the aggregated Fermatean risk assessment matrix (regarding assessing "Casting section" hazards)

Table 5 Distance from FFPIS and FFNIS and final revised closeness values of each hazard in the "Casting section"

\begin{tabular}{lllll}
\hline Hazard & $D\left(S_{i}, S^{+}\right)$ & $D\left(S_{i}, S^{-}\right)$ & $\xi\left(S_{i}\right)$ & Rank \\
\hline TO1 & 0.504 & 0.053 & -7.195 & 6 \\
TO2 & 0.470 & 0.087 & -6.621 & 4 \\
TO3 & 0.207 & 0.350 & -2.269 & 2 \\
TO4 & 0.479 & 0.089 & -6.747 & 5 \\
TO5 & 0.069 & 0.483 & 0.000 & 1 \\
TO6 & 0.214 & 0.339 & -2.392 & 3 \\
\hline
\end{tabular}

existed measure for MSH2. In addition to these notices, personnel going to this area should be warned. Stacking rules handbook has been created to prevent MSH3. Stacks should be checked more frequently, and boundary lines indicating the stack upper limit should be drawn. No smoking signs were placed in the area to prevent MSH1. As an additional measure for this hazard, sanctions can be applied to smokers.

Control measures for the "Production section" hazard (PU4, PU7, PU6): the protective equipment of the guillotine shears should be checked at regular intervals to minimize the PU4. Scissors protective equipment is used for PU7. In addition, measure, a warning system can set up to notify 


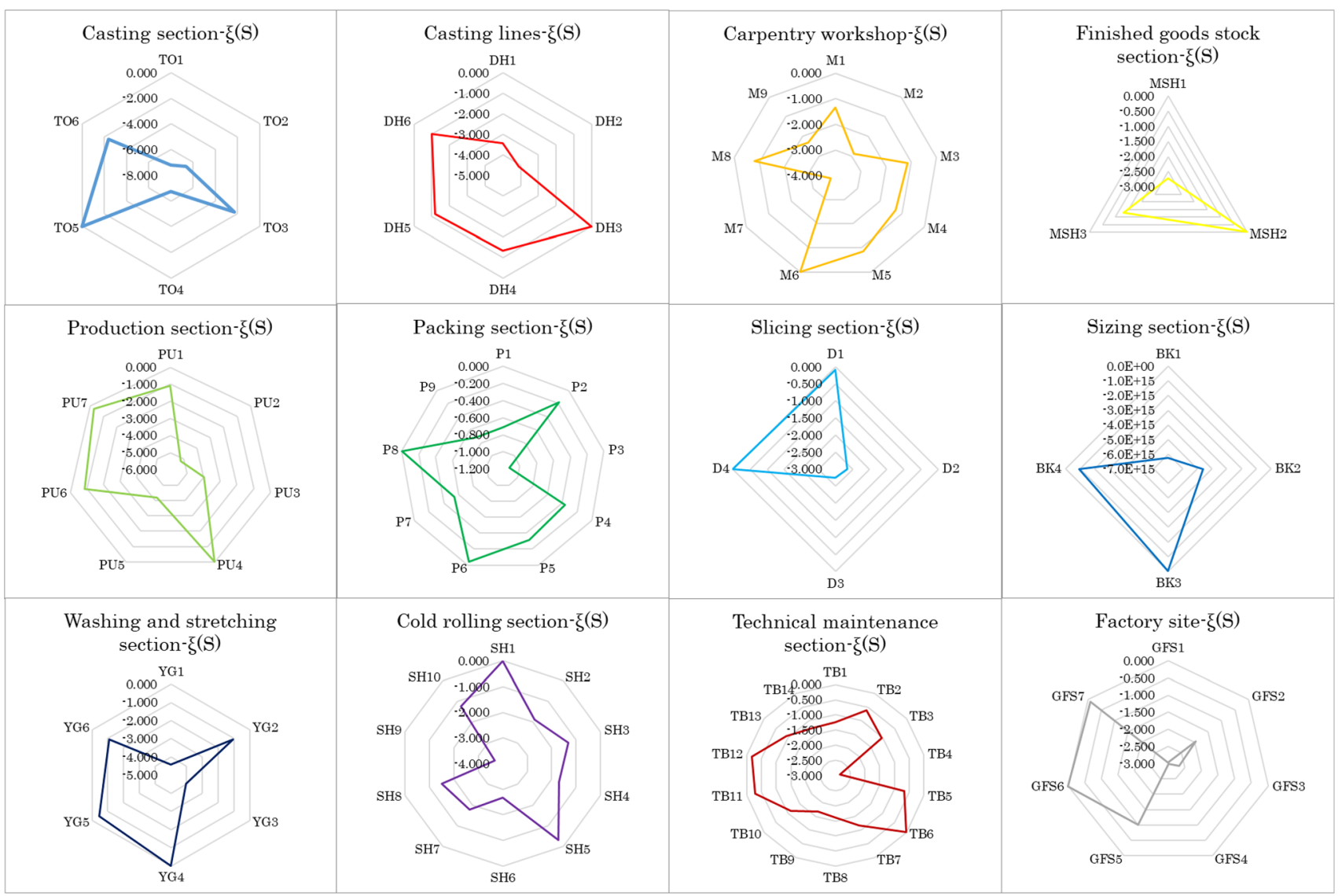

Fig. 4 Final FF-TOPSIS revised closeness coefficients of hazards in each section of the plant

whether the protective equipment is permanently attached or not. For PU6, a protective cover can be made on the roller straightener's material entrance area against the risk of handarm grabbing.

Control measures for the "Packing section" hazard (P8, $\mathrm{P} 6, \mathrm{P} 2)$ : to prevent $\mathrm{P} 8$, personnel are regularly informed about the dangers of their work. Moreover, by marking the crane's working area, it can be ensured that the personnel are not present in this area. For P6, the staff has been given carrying instruction. In addition, a carrying handbook can be created by considering ergonomic environments. For P2, the cabinets' ventilation was opened, and gas detectors were installed in the system. A new system can be developed to monitor harmful gases in the system continuously.

Control measures for the "Slicing section" hazard (D4, D1, D2): employees wear earplugs suitable for the job to decrease the effects of D4. Earphones with higher insulation can be used as an additional measure. An emergency stop button has been added to the system for D1. To improve this measure, an emergency stop device integrated into the pressure sensors can be arranged. For D2, it has put a protective obstacle to prevent manual contact with the cutter blade. On the other side, protective plates can be added to the system to reduce the hazard.

Control measures for the "Sizing section" hazard (BK3, BK4, BK2): for BK3, the company currently uses emergency stop buttons. Besides this precaution, the operators should be prevented from approaching the rotating parts. For this purpose, fields that cannot be entered can be marked. Earplugs are used for BK4. As an additional comment, the cutting section of thick plates in the workplace can be isolated. Corsets were provided to the employees to prevent back and spine discomfort for the BK2. In addition, automatic cranes can be used to transport the plates.

Control measures for the "Washing and stretching section" hazard (YG4, YG5, YG6): in line with the measures taken for YG4, cleaning is performed only when the roller speeds are at minimum and under the control of responsible personnel. This hazard can be minimized if an automatic cleaning device is installed in this section. Emergency Stop Buttons have been added to the system for YG5. As well as this measure, emergency stop wires surrounding the line can be applied. For LA6, personnel use of earplugs is encouraged. Furthermore, protective equipment with high sound insulation can be used. 


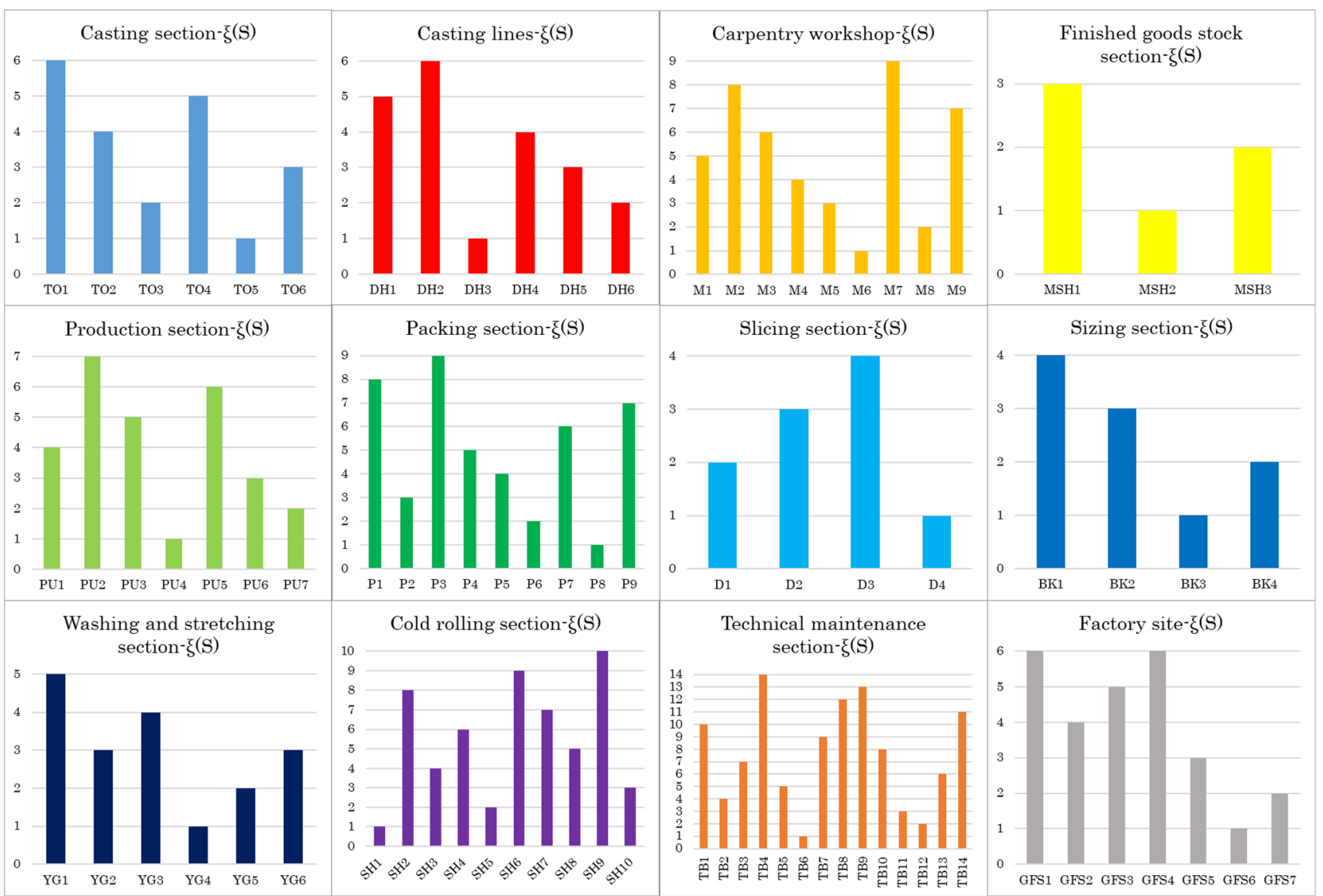

Fig. 5 Ranking of hazards in each section of the plant

Control measures for the "Cold rolling section" hazard (SH1, SH5, SH10): for SH1, the enterprise has created "Safety Data Sheets" for the rolling oil and additives used. In addition, employees working in the Operations area can use masks suitable for work. This section should also be continuously ventilated to ensure that toxic gases are removed from the system. Periodic maintenance of the fire test system is made for SH5. In addition, regular fire drills can be made for this area, and personnel training can be provided. Bobbin trolley operating instructions have been created for SH10. In addition to this measure, coil car maneuver lines can be drawn.

Control measures for the "Technical maintenance section" hazard (TB6, TB12, TB11): for TB6, it is aimed to prevent the formation of the slippery ground using oil absorbers in the work area. In addition, oil collecting chambers in appropriate sizes can be made under the roller chocks. For TB12, protective glasses suitable for the current preventive measure are used. A fixed protective transparent plate should be mounted on the cutting tool as a creative precaution for this hazard. For TB11, necessary warnings are made for the operators, and the bearings are checked. It should also be ensured that the clearance between the cutting edges of the bearings is $3 \mathrm{~mm}$.

Control measures for the "Factory site" hazard (GFS6, GFS7, GFS5): For GFS6, the control of the coupling guards" fitting is carried out by the responsible personnel. Moreover, this control process should be standardized and its sustainability should be ensured. A detection report has been created for GFS7 and reported to hazard managers. Furthermore, by evaluating the detection reports, warning signs can be set for the most stylish situations. For the GFS5, after the operator has located the tubes, they are fixed to prevent movement. Motion sensors can also be placed in these tubes to report this situation to managers when necessary.

\section{Comparative analysis of the results}

To illustrate the advantages of our FF-TOPSIS approach, this study compared the crisp TOPSIS, grey TOPSIS, and general fuzzy TOPSIS techniques. The ranking results of the 85 potential hazards of the four TOPSIS techniques, as shown in Figs. 6 and 7. The crisp TOPSIS does not 
consider data/information uncertainty, converting experts' judgments into a crisp value. The grey TOPSIS and general fuzzy TOPSIS reflect the uncertainty of experts' assessment environment but do not measure the degree of membership and non-membership of the evaluated events simultaneously. The relative closeness index of each hazard obtained by these four techniques are different, and the priorities of 85 potential hazards are inconsistent.

The analysis results presented in Figs. 6 and 7 show the differences between the four TOPSIS techniques. In the Casting and Sizing sections, the orderings are determined precisely the same. Spearman's Rho coefficients are calculated and presented in Table 6 to check whether the rankings for other sections were statistically significant. It was concluded that there is a significant relationship between the TOPSIS methods.
In addition, we have compiled a comparison table to summarize the differences of various TOPSIS techniques, as shown in Table 7. According to Table 7, none of those TOPSIS extensions is sufficient for demonstrating the risk assessment decision-making problems with Fermatean fuzzy data. The amount of uncertainty information covered by FF-TOPSIS is relatively higher than IF-TOPSIS and PF-TOPSIS. The Fermatean fuzzy linguistic scale, which we suggested in this study, reflects the expert's subjective judgment in a broader perspective than other TOPSIS improvements. This is an important advantage of FF-TOPSIS.

Furthermore, the FF-TOPSIS was also compared with other popular MCDM methods, namely fuzzy SAW, fuzzy WASPAS, fuzzy MOORA, and fuzzy ARAS. As presented in Table 8, according to the correlation coefficient of overall
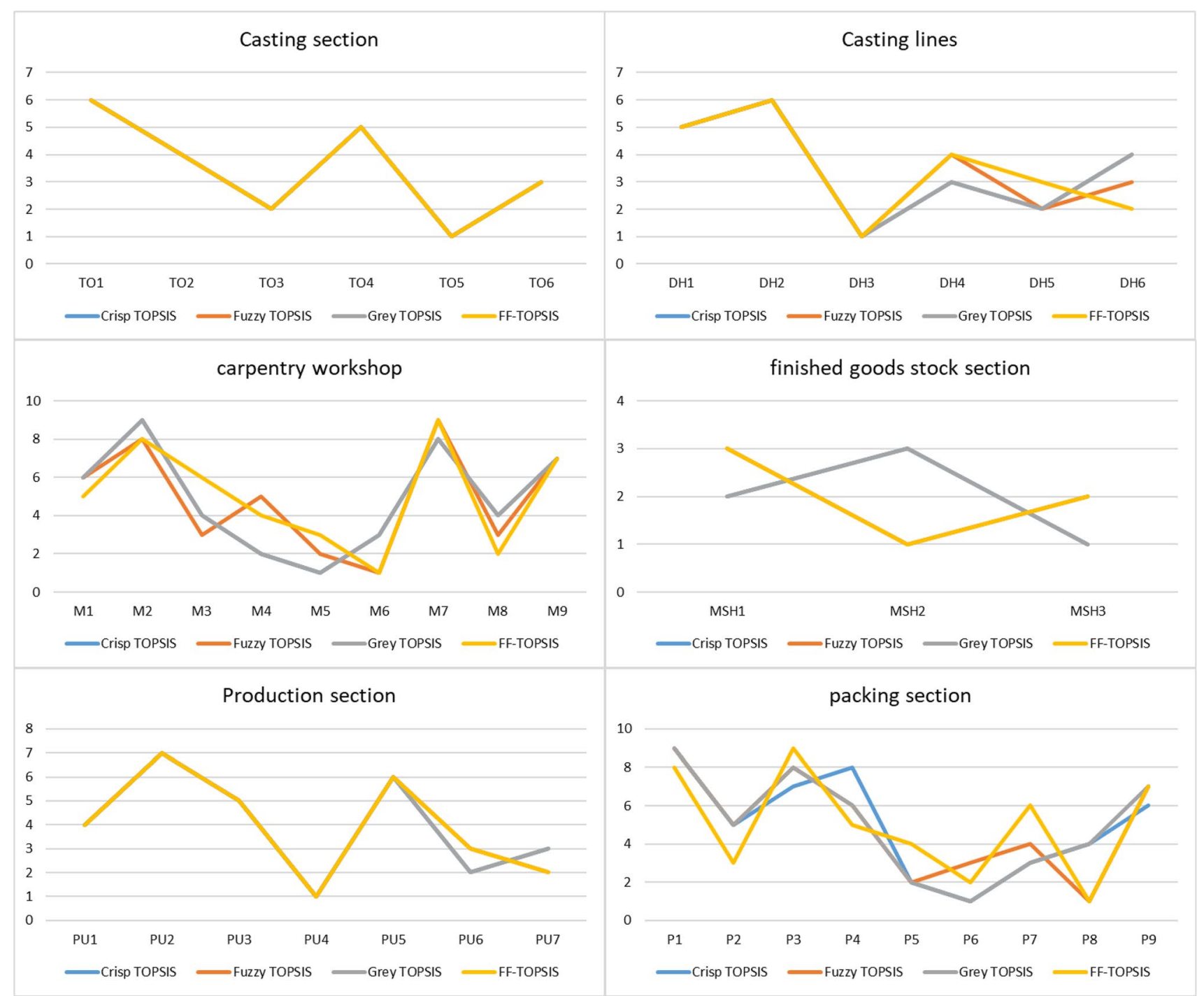

Fig. 6 Ranking results of the 85 potential hazards of the four TOPSIS techniques

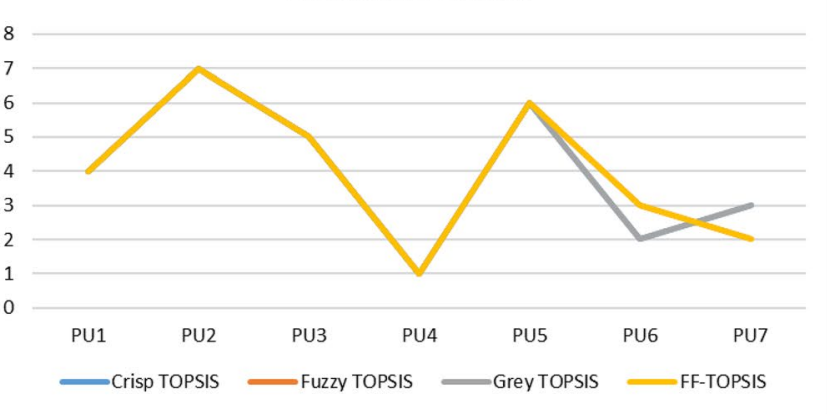




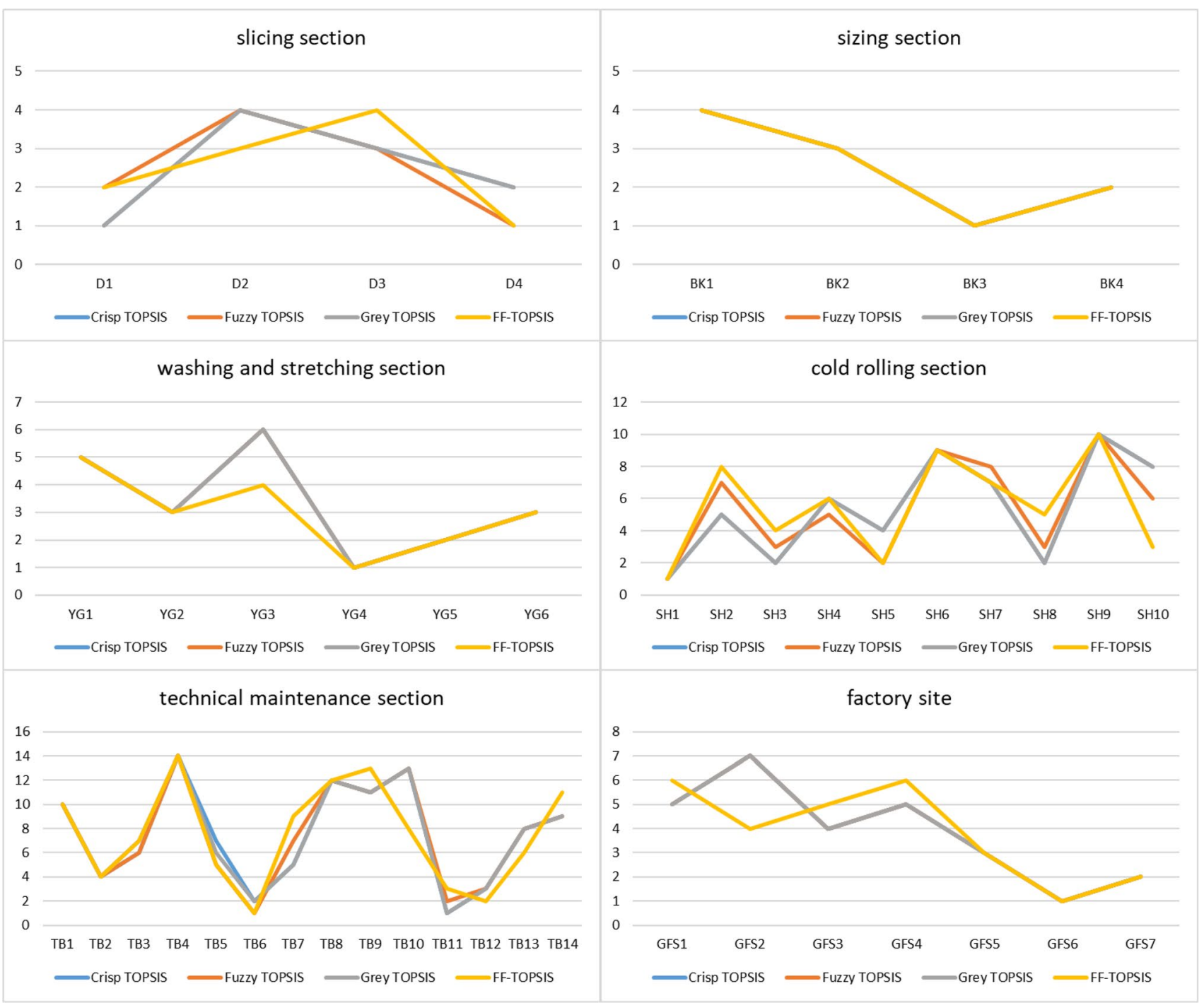

Fig. 7 Ranking results of the 85 potential hazards of the four TOPSIS techniques (continued)

Table 6 Spearman's Rho coefficients of TOPSIS methods

\begin{tabular}{|c|c|c|c|c|}
\hline Section & & Crisp TOPSIS & Fuzzy TOPSIS & Grey TOPSIS \\
\hline Casting lines & FF-TOPSIS & 0.829 & 0.943 & 0.829 \\
\hline Carpentry workshop & & 0.803 & 0.904 & 0.829 \\
\hline Production section & & 0.964 & 1.000 & 0.964 \\
\hline Packing section & & 0.650 & 0.867 & 0.750 \\
\hline Slicing section & & 0.600 & 0.800 & 0.600 \\
\hline Washing and stretching section & & 0.941 & 0.941 & 0.941 \\
\hline Cold rolling section & & 0.717 & 0.912 & 0.717 \\
\hline Technical maintenance section & & 0.859 & 0.903 & 0.868 \\
\hline Factory site & & 0.782 & 0.782 & 0.782 \\
\hline
\end{tabular}

ranking, the results of FF-TOPSIS and the other four MCDM methods are not completely consistent. As mentioned in the introduction section, TOPSIS is based on calculating the distance between each evaluated item and the PIS and NIS.
Undoubtedly, FF-TOPSIS considers more reference parameters than other methods, so the ranking results are relatively reliable. 
Table 7 Description of the differences between the six TOPSIS techniques

\begin{tabular}{lllll}
\hline Extension of TOPSIS & Data type & $\begin{array}{l}\text { Considers informa- } \\
\text { tion uncertainty }\end{array}$ & $\begin{array}{l}\text { Measure the degree of member- } \\
\text { ship and non-membership }\end{array}$ & $\begin{array}{l}\text { Amount of uncer- } \\
\text { tainty information } \\
\text { covered }\end{array}$ \\
\hline Crisp TOPSIS & Crisp & No & No & Low \\
Grey TOPSIS & Grey numbers & Yes & No & Low \\
General fuzzy TOPSIS & Fuzzy numbers & Yes & No & Low \\
IF-TOPSIS & Intuitionistic fuzzy numbers & Yes & Yes & Low \\
PF-TOPSIS & Pythagorean fuzzy numbers & Yes & Yes & Hes \\
FF-TOPSIS & Fermatean fuzzy numbers & Yes & High \\
\hline
\end{tabular}

Table 8 The correlation coefficient of the overall ranking of five methods

\begin{tabular}{llllll}
\hline & FF-TOPSIS & Fuzzy SAW & Fuzzy WASPAS & $\begin{array}{l}\text { Fuzzy } \\
\text { MOORA }\end{array}$ & Fuzzy ARAS \\
\hline FF-TOPSIS & 1 & & & & \\
Fuzzy SAW & 0.9298 & 1 & 1 & & \\
Fuzzy WASPAS & 0.9292 & 0.9882 & 1 & 1 & 1 \\
Fuzzy MOORA & 0.9298 & 1 & 0.9882 & 1 & 1 \\
Fuzzy ARAS & 0.9298 & 1 & 0.9882 & & \\
\hline
\end{tabular}

\section{Conclusion}

Activities in the process industry contain several hazards, from harmful chemicals to mechanical risks. These hazards are addressed as originating from the product, process, human and working environment, and the risks associated with them are evaluated and prioritized. In this context, comprehensive methods developed beyond traditional risk assessment methods and transform traditional approaches' disadvantageous features into advantages are being developed. Previous studies revealed that traditional methods require a time-consuming and burdensome data collection process and do not reflect experts' subjective evaluations well enough. Concerning this situation, it has become important to suggest risk assessment methods based on fuzzy decision-making methods and to ensure their applicability.

Therefore, the current study suggests a soft computing approach that can address these concerns. This approach is provided by the integration of FFSs and TOPSIS method. The proposed model provides a framework for prioritizing risks in the aluminum plate production process based on numerous expert judgments. To show the applicability of the model, the risks arising in 12 different sections in the observed plant were prioritized by the proposed framework. Numerical results of the study demonstrate that the most important hazards and associated risks are stemmed from TO5, DH3, M6, MSH2, PU4, P8, D4, BK3, SH1, TB6, YG4. Reducing these risk factors will significantly reduce the risks of production. It has been concluded that the most critical risks are human-induced, and the use of appropriate protective equipment is necessary to minimize the risks.

In summary, the main contributions of the proposed approach are as follows.

(i) TOPSIS method with FFSs has been implemented in a real-life manufacturing risk assessment problem for the first time in the literature.

(ii) In the procedural steps of FF-TOPSIS, a new fuzzy Fermatean linguistic scale is developed, enabling experts easily disclose their opinions.

(iii) The demonstrated case study is adaptable by any practitioners and researchers in the industry for their risk assessment problems.

(iv) A benchmarking study with three different TOPSIS versions is provided to observe variations in risk ranking. For this aim, crisp TOPSIS, fuzzy TOPSIS, and grey TOPSIS are applied to the problem.

Besides these contributions to the literature, the current study still has some limitations that need to be addressed. Although this may be determined in this way in the context of the needs of the sector being worked on, when a new sector/process is adapted, additional risk parameters such as detectability, cost, prevention, effectiveness, sensitivity to non-usage of PPE, and sensitivity to no-application of maintenance may need to be taken into account. In this case, the weight assignment should be made by handling these new parameters by some comprehensive pairwise 
comparison-based methods. In this case, the BWM can be considered in future studies to calculate risk parameter weights using fewer pairwise comparisons and providing more consistent expert assessments.

\section{Declaration}

Conflict of interest The authors declare that they have no conflict of interests.

Open Access This article is licensed under a Creative Commons Attribution 4.0 International License, which permits use, sharing, adaptation, distribution and reproduction in any medium or format, as long as you give appropriate credit to the original author(s) and the source, provide a link to the Creative Commons licence, and indicate if changes were made. The images or other third party material in this article are included in the article's Creative Commons licence, unless indicated otherwise in a credit line to the material. If material is not included in the article's Creative Commons licence and your intended use is not permitted by statutory regulation or exceeds the permitted use, you will need to obtain permission directly from the copyright holder. To view a copy of this licence, visit http://creativecommons.org/licenses/by/4.0/.

\section{References}

1. Akram M, Shahzadi G, Ahmadini AAH (2020) Decision-making framework for an effective sanitizer to reduce COVID-19 under Fermatean fuzzy environment. J Math. https://doi.org/10.1155/ 2020/3263407

2. Ali Y, Awan MA, Bilal M, Khan J, Petrillo A, Khan AA (2019) Risk assessment of China-Pakistan fiber optic project (CPFOP) in the light of multicriteria decision making (MCDM). Adv Eng Inform 40:36-45

3. Atanassov KT (1999) Intuitionistic fuzzy sets. In Intuitionistic fuzzy sets. Physica, Heidelberg, pp 1-137

4. Aven T (2016) Risk assessment and risk management: Review of recent advances on their foundation. Eur J Oper Res 253(1):1-13

5. Aydemir SB, Gunduz SY Fermatean fuzzy TOPSIS method with Dombi aggregation operators and its application in multicriteria decision making. J Intell Fuzzy Syst 39(1):851-869

6. Başhan V, Demirel H, Gul M (2020) An FMEA-based TOPSIS approach under single valued neutrosophic sets for maritime risk evaluation: the case of ship navigation safety. Soft Comput 24(24):18749-18764

7. Berhan E (2020) Prevalence of occupational accident; and injuries and their associated factors in iron, steel and metal manufacturing industries in Addis Ababa. Cogent Eng 7(1):1723211

8. Braglia M, Gabbrielli R, Marrazzini L (2020) Risk Failure Deployment: a novel integrated tool to prioritize corrective actions in failure mode and effects analysis. Qual Reliab Eng Int 37(2):433-450

9. Cai Y, Li F, Zhang J, Wu Z (2018) Occupational health risk assessment in the electronics industry in China based on the occupational classification method and EPA model. Int J Environ Res Public Health 15(10):2061

10. Celik E, Gul M (2021) Hazard identification, risk assessment and control for dam construction safety using an integrated BWM and MARCOS approach under interval type-2 fuzzy sets environment. Autom Const 127:103699
11. Dabbagh R, Yousefi S (2019) A hybrid decision-making approach based on FCM and MOORA for occupational health and safety risk analysis. J Safety Res 71:111-123

12. Delice EK, Can GF (2020) A new approach for ergonomic risk assessment integrating KEMIRA, best-worst and MCDM methods. Soft Comput 24(19):15093-15110

13. Folch-Calvo M, Brocal F, Sebastián MA (2019) New risk methodology based on control charts to assess occupational risks in manufacturing processes. Materials 12(22):3722

14. Garg H, Shahzadi G, Akram M (2020) Decision-making analysis based on Fermatean fuzzy Yager aggregation operators with application in COVID-19 testing facility. Math Prob Eng. https:// doi.org/10.1155/2020/7279027

15. Gul M (2020) A fuzzy-based occupational health and safety risk assessment framework and a case study in an international port authority. J Mar Eng Technol 19(4):161-175

16. Gul M, Ak MF (2020) Assessment of occupational risks from human health and environmental perspectives: a new integrated approach and its application using fuzzy BWM and fuzzy MAIRCA. Stoch Env Res Risk Assess 34:1231-1262

17. Gul M, Ak MF (2021) A modified failure modes and effects analysis using interval-valued spherical fuzzy extension of TOPSIS method: case study in a marble manufacturing facility. Soft Comput 25(8):6157-6178

18. Gul M, Mete S, Serin F, Celik E (2021) Fine-Kinney-based occupational risk assessment using hexagonal fuzzy MULTIMOORA. In Fine-Kinney-based fuzzy multi-criteria occupational risk assessment. Springer, Cham, pp 91-110

19. Gul M, Yucesan M, Celik E (2020) A manufacturing failure mode and effect analysis based on fuzzy and probabilistic risk analysis. Appl Soft Comput 96:106689

20. Kabir S, Yazdi M, Aizpurua JI, Papadopoulos Y (2018) Uncertainty-aware dynamic reliability analysis framework for complex systems. IEEE Access 6:29499-29515

21. Karatop B, Taşkan B, Adar E, Kubat C (2020) Decision analysis related to the renewable energy investments in Turkey based on a fuzzy AHP-EDAS-Fuzzy FMEA approach. Comput Ind Eng $151: 106958$

22. Li X, Gül M, Al-Hussein M (2019) An improved physical demand analysis framework based on ergonomic risk assessment tools for the manufacturing industry. Int J Ind Ergon 70:58-69

23. Liu D, Liu Y, Chen X (2019) Fermatean fuzzy linguistic set and its application in multicriteria decision making. Int J Intell Syst 34(5):878-894

24. Liu D, Liu Y, Wang L (2019) Distance measure for Fermatean fuzzy linguistic term sets based on linguistic scale function: an illustration of the TODIM and TOPSIS methods. Int J Intell Syst 34(11):2807-2834

25. Liu HC, Chen XQ, Duan CY, Wang YM (2019) Failure mode and effect analysis using multicriteria decision making methods: a systematic literature review. Comput Ind Eng 135:881-897

26. Liu R, Hou LX, Liu HC, Lin W (2020) Occupational health and safety risk assessment using an integrated SWARA-MABAC model under bipolar fuzzy environment. Comput Appl Math 39(4):1-17

27. Liu R, Liu Z, Liu HC, Shi H (2021) An improved alternative queuing method for occupational health and safety risk assessment and its application to construction excavation. Autom Const 126:103672

28. Liu R, Mou X, Liu HC (2021) New model for occupational health and safety risk assessment based on combination weighting and uncertain linguistic information. IISE Trans Occup Ergon Human Fact. https://doi.org/10.1080/24725838.2021.1875519

29. Lo HW, Liou JJ, Huang CN, Chuang YC (2019) A novel failure mode and effect analysis model for machine tool risk analysis. Reliab Eng Syst Saf 183:173-183 
30. Mzougui I, Carpitella S, Certa A, Felsoufi ZE, Izquierdo J (2020) Assessing supply chain risks in the automotive industry through a modified MCDM-based FMECA. Processes 8(5):579

31. Realyvásquez-Vargas A, Arredondo-Soto KC, García-Alcaraz JL, Márquez-Lobato BY, Cruz-García J (2019) Introduction and configuration of a collaborative robot in an assembly task as a means to decrease occupational risks and increase efficiency in a manufacturing company. Robot Comput-Integr Manuf 57:315-328

32. Rezaee MJ, Yousefi S, Eshkevari M, Valipour M, Saberi M (2020) Risk analysis of health, safety and environment in chemical industry integrating linguistic FMEA, fuzzy inference system and fuzzy DEA. Stoch Env Res Risk Assess 34(1):201-218

33. Rezaei J, Kothadiya O, Tavasszy L, Kroesen M (2018) Quality assessment of airline baggage handling systems using SERVQUAL and BWM. Tour Manage 66:85-93

34. Seifi Azad Mard HR, Estiri A, Hadadi P, Seifi Azad Mard M (2017) Occupational risk assessment in the construction industry in Iran. Int J Occup Saf Ergon 23(4):570-577

35. Senapati T, Yager RR (2019) Fermatean fuzzy weighted averaging/geometric operators and its application in multicriteria decision-making methods. Eng Appl Artif Intell 85:112-121

36. Senapati T, Yager RR (2019) Some new operations over Fermatean fuzzy numbers and application of Fermatean fuzzy WPM in multiple criteria decision making. Informatica 30(2):391-412

37. Senapati T, Yager RR (2020) Fermatean fuzzy sets. J Ambient Intell Humaniz Comput 11(2):663-674

38. Sergi D, Sari IU (2020) Fuzzy capital budgeting using fermatean fuzzy sets. In International Conference on Intelligent and Fuzzy Systems. Springer, Cham, pp 448-456

39. Silambarasan I (2020) New operators for Fermatean fuzzy sets. Ann Commun Math 3(2):116
40. Sonnemann G, Tsang M, Schuhmacher M (eds) (2018) Integrated life-cycle and risk assessment for industrial processes and products. CRC Press

41. URL-1. http://www.sgk.gov.tr/wps/portal/sgk/tr/kurumsal/istat istik/sgk_istatistik_yilliklari. Accessed date 29.04.2021

42. Wang H, Wang X, Wang L (2019) Multicriteria decision making based on Archimedean Bonferroni mean operators of hesitant Fermatean 2-tuple linguistic terms. Complexity. https://doi.org/10. $1155 / 2019 / 5705907$

43. Yager RR (2013) Pythagorean fuzzy subsets. In 2013 joint IFSA world congress and NAFIPS annual meeting (IFSA/NAFIPS) (pp 57-61). IEEE

44. Yazdi M (2019) Footprint of knowledge acquisition improvement in failure diagnosis analysis. Qual Reliab Eng Int 35(1):405-422

45. Yousefi S, Alizadeh A, Hayati J, Baghery M (2018) HSE risk prioritization using robust DEA-FMEA approach with undesirable outputs: a study of automotive parts industry in Iran. Saf Sci 102:144-158

46. Yousefi S, Jahangoshai Rezaee M, Moradi A (2020) Causal effect analysis of logistics processes risks in manufacturing industries using sequential multi-stage fuzzy cognitive map: a case study. Int J Comput Integr Manuf 33(10-11):1055-1075

47. Yucesan M, Gul M, Celik E (2021) A holistic FMEA approach by fuzzy-based Bayesian network and best-worst method. Complex Intell Syst 7(3):1547-1564

Publisher's Note Springer Nature remains neutral with regard to jurisdictional claims in published maps and institutional affiliations. 